\title{
Early invasive vulvar squamous cell carcinoma arising in a woman with vulvar pemphigus vulgaris and systemic lupus erythematosus
}

\author{
Giuseppe Bifulco1', Vincenzo D Mandato*1, Roberto Piccoli1, Pierluigi Giampaolino'1, Chiara Mignogna2, \\ Michele D Mignogna ${ }^{3}$, Luigi Costagliola and Carmine Nappi ${ }^{1}$
}

\begin{abstract}
Background: Pemphigus vulgaris (PV) is an autoimmune blistering disease of the skin and mucous membranes. Genital involvement occurs when most other common sites are concurrently affected or are in remission. Systemic lupus erythematosus (SLE) is an autoimmune disease that may affect many parts of the body and the skin with occasional bullous lesions. Pemphigus vulgaris and SLE may be associated, albeit rarely. Here, we report the first case of a woman affected with SLE presenting with early invasive squamous cell carcinoma (SCC) arising from Pemphigus Vulgaris of the vulva.

Case presentation: A 27-year-old Caucasian woman was admitted to our Gynaecology Unit for bleeding vegetant lesions of the vulva. Her history was characterized by systemic lupus erythematosus and PV. Biopsy showed concomitant PV and vulvar intraepithelial neoplasia (VIN) grade 3. One month later a new biopsy revealed progression from VIN 3 to early SCC. Despite chemotherapy, no remission of disease was observed. She died six months after diagnosis

Conclusion: Our case underlines PV as another chronic inflammatory disease of the lower genital tract predisposing to VIN-SCC. It suggests the need for careful follow-up of patients with chronic inflammatory disease, especially when concomitant autoimmune disorders are present. Moreover, a biopsy should be always performed if there are PV lesions because of the possibility of neoplastic disease.
\end{abstract}

\section{Background}

Pemphigus vulgaris (PV) is an autoimmune blistering disease of the skin and mucous membranes characterized by the presence of autoantibodies targeting desmoglein 3, a surface antigen of keratinocytes involved in maintaining cell-cell junctions [1]. Its incidence is 0.1-3.2 cases per 100,000 individuals per year. PV typically runs a chronic course, with blisters, painful erosions and ulcers on the mucosa and skin $[2,3]$. The sites most commonly involved are the oral mucosa, pharynx, larynx, oesophagus, conjunctiva and anal mucosa [1-4]. Involvement of the genital tract in women with PV has rarely been reported [5]. Usually, genital involvement occurs when most other

\footnotetext{
*Correspondence: dariomandato@virgilio.it

1 Department of Gynecology and Obstetrics, and Pathophysiology of Human Reproduction, University of Naples "Federico II", Italy

Full list of author information is available at the end of the article
}

common sites are concurrently affected or are in remission $[1,6]$.

Systemic lupus erythematosus (SLE) is an autoimmune disease that may affect many parts of the body and the skin with occasional bullous lesions. Pemphigus vulgaris may exceptionally be associated with other blistering diseases such as SLE [7].

Here, we report a rare case of a woman affected with SLE presenting with early invasive squamous cell carcinoma (SCC) arising from Pemphigus Vulgaris of the vulva.

\section{Case presentation}

A 27-year-old Caucasian woman was admitted to our Gynaecology Unit (February 2007) for bleeding vegetant lesions of the vulva. She had no family history of autoimmune disease. Her history was characterized by concomi- 
tant SLE and recurrent blisters and erosions affecting the oral mucosa and skin diagnosed as severe PV. She had been treated with high and prolonged doses of both systemic corticosteroids and other immunosuppressive drugs (Prednisone $100 \mathrm{mg} /$ day $\times 69$ months; Azathioprine $80 \mathrm{mg} /$ day $\times 51$ months; Cyclophosphamide $83 \mathrm{mg} /$ day $\times 15$ months; Cyclosporine $300 \mathrm{mg} /$ day $\times 2$ months)

She had had necrosis of the femoral and humerus necks, osteortrosis, arthritis, osteoporosis and recurrent infections. Most recently, at gynaecological examination a thick area associated with ulcerative necrotic areas, and atypical vessels were revealed. Vulvar biopsy diagnosed PV. The epidermidis was arranged in a micropapillary pattern with combined aspects of acantholytic and atypical cells. Multiple areas of acantholytic clefts separated the upper part of the epidermidis from the basal keratinocytes. Unusually, dysplastic cells with atypical mitoses were present (Figure 1). Because she was virgin, She never had a pap smear and we did not perform it.

On March 2007 the lesion had extended to the perineal and groin area (Figure 2). Biopsy revealed a vulvar intraepithelial neoplasia (VIN) grade 3 with microinvasive disease. The SCC vertical invasion of the stroma was less than $1 \mathrm{~mm}$.

Hyperplastic epidermidis was characterized by the formation of acantholytic clefts and the presence of displastic cells and mitotic activity. Focal infiltrative aspects were present (Figure 3).

Positron Emission Tomography (PET) and Magnetic Resonance Imaging (MRI) showed no metastatic disease.

Current therapy was based on High dose human immunoglobulins (IVIg).

IVIg 5\% solution were infused intravenously with an electronic pumping device at a total dose of $2 \mathrm{~g} / \mathrm{kg}$ per cycle divided into three equal doses, administered over 3 consecutive days. The infusion was administered slowly at not more than $50 \mathrm{mg} / \mathrm{kg}$ per hour.

The therapy improved the immunological PV but not the clinical PV. The antibody titer showed a progressive decrease (pre-IVIg titer was of 1:1280; during IVIg titer was of 1: 640; post IVIg titer was of 1:80)

Based on biopsy findings, a wide and deep excision of the primary tumor was required but our patient was classified as ASA IV at preoperative evaluation. She presented a $25 \mathrm{~kg}$ weight loss, a worsening of the clinical conditions with a high risk of nonhealing wound and postopearative infection so combined chemotherapy was preferred to surgical approach. She received six cycles of cisplatin plus 5-fluorouracil. The doses and schedule was cisplatin $75 \mathrm{mg} / \mathrm{m} 2$ on day 1 and 5 -fluorouracil $800 \mathrm{mg} /$ $\mathrm{m} 2$ on day 2 to 5 every three weeks.

Despite the chemotherapy there was no remission of the lesion, though no local extension was observed (Fig-

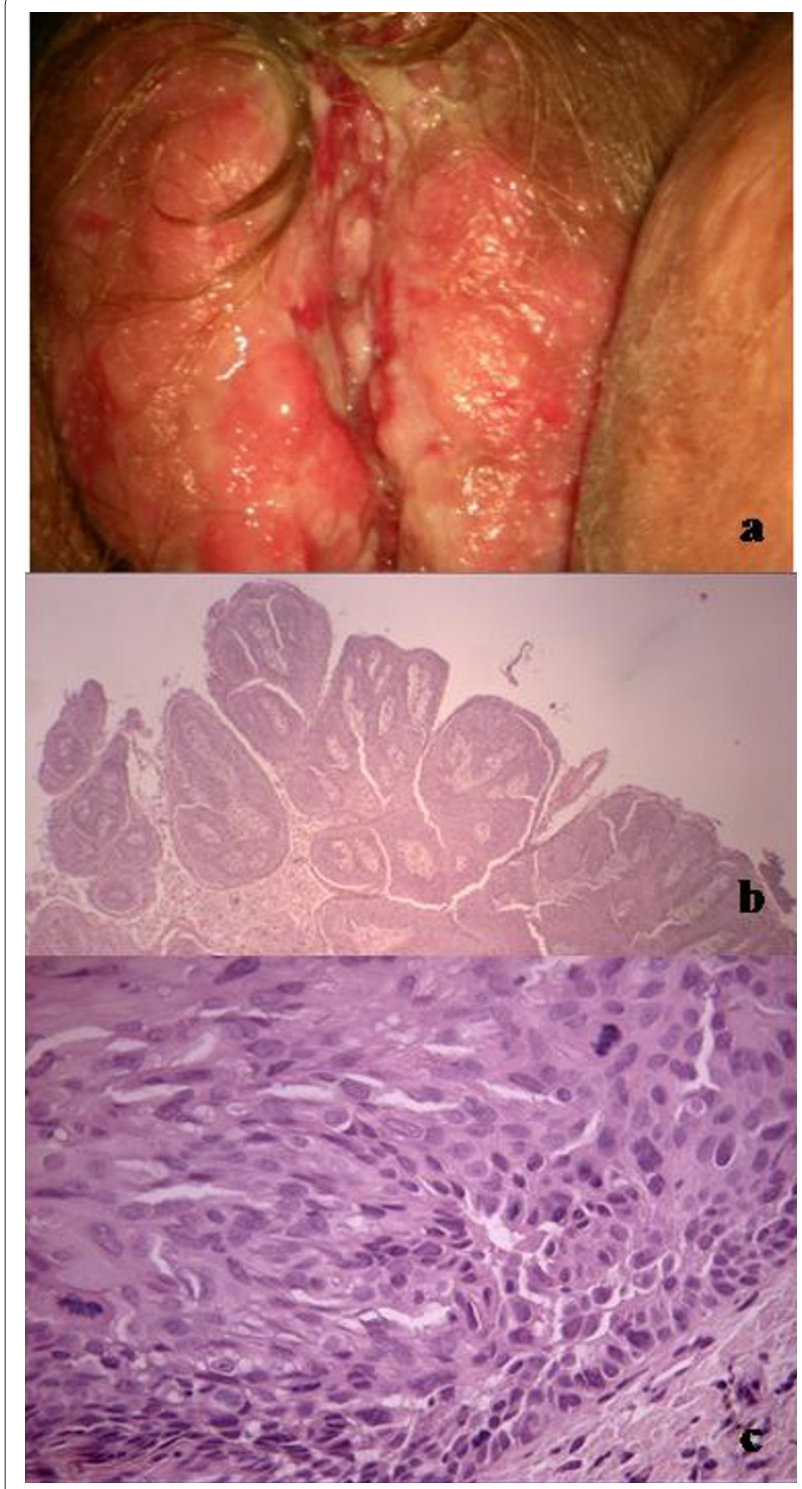

Figure 1 Macroscopic and microscopy findings at diagnosis: (a): vulvar bleeding vegetants lesions; (b): micropapillary pattern; (c): acantholysis and mitosis

ure 4). A new biopsy (September 2007) revealed atypical and acantholytic cells dispersed into a neutrophil and red blood cell background (Figure 5). Two months later she died from cardiac arrest due to worsening of her general condition. but no post mortem examination was performed because her parents refused.

\section{Discussion}

Pemphigus vulgaris (PV) is a chronic autoimmune disease with a mortality rate less than $10 \%$ following treatment with systemic corticosteroids and immunosuppressive agents [8]. It mainly affects elderly persons. PV is diagnosed on the basis of clinical appear- 

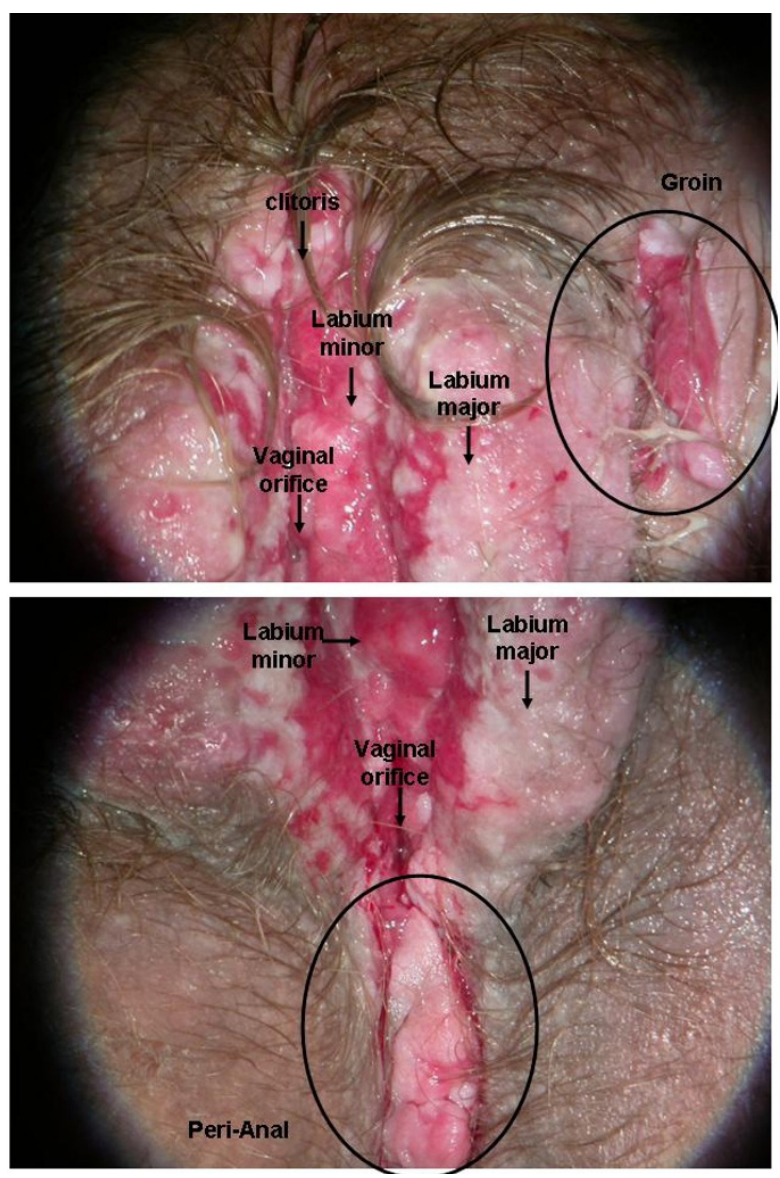

Figure $\mathbf{2}$ Macroscopic findings at one month from diagnosis: lesion was extended to peri-anal area and groin area.

ance, histology, and immunofluorescence studies. Histology demonstrates loss of cell-cell adhesion (acantholysis) above the basal layer of the epidermis. Immunoglobulin $\mathrm{G}$ is detected on keratinocyte cell surfaces by direct immunofluorescence in nearly all patients, although sera from PV patients contain antibodies that bind to keratinocyte cell surface antigens on indirect immunofluorescence. The pathogenic antibodies are directed against the keratinocyte cell surface molecules desmoglein 1 and 3. An immunoblot assay or enzyme-linked immunosorbent assay may also be used to detect antibodies.

PV is rarely associated with SLE; the association has been reported in the literature in only 4 females [9-12] and 1 male [7]. This is the fifth case of PV associated with SLE. More common blistering skin lesions associated with SLE are paraneoplastic pemphigus, pemphigus erythematosus and drug-induced pemphigus. Paraneoplastic pemphigus consists of painful mucosal ulcerations and a polymorphic blistering eruption on the trunk and extremities, and a characteristic autoantibody pattern that usually resolves after tumour removal [13]. Pemphi-

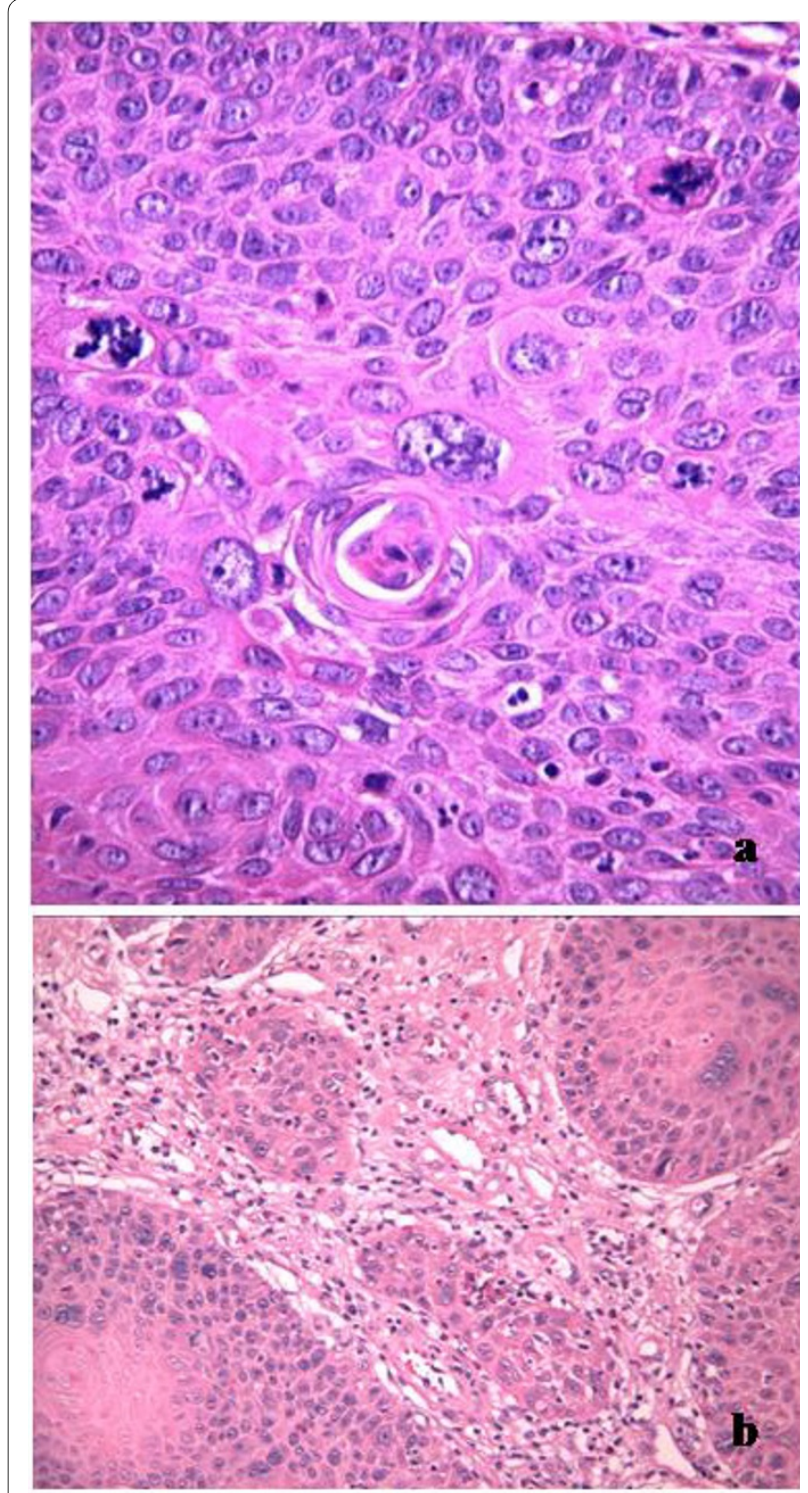

Figure 3 Microscopy findings at one month from diagnosis: (a): atypical mitosis; (b): infiltrative aspects were present.

gus erythematosus is characterized by facial eruption and bullous lesions on the chest, upper back and intertriginous areas with minimal SLE manifestations [14]. Druginduced pemphigus has a course similar to PV but resolves after discontinuation of the associated drug and is histologically different. PV produces deeper vesicles as a result of the acantholysis in the suprabasal layer of the epidermis, whilst acantholysis in drug-induced pemphigus occurs in the corneal layer.

Therefore, we excluded pemphigus erythematosus because of the severe SLE manifestations in our patient; on the other hand, we excluded drug-induced pemphigus because histologically the epidermis was deeply affected, 


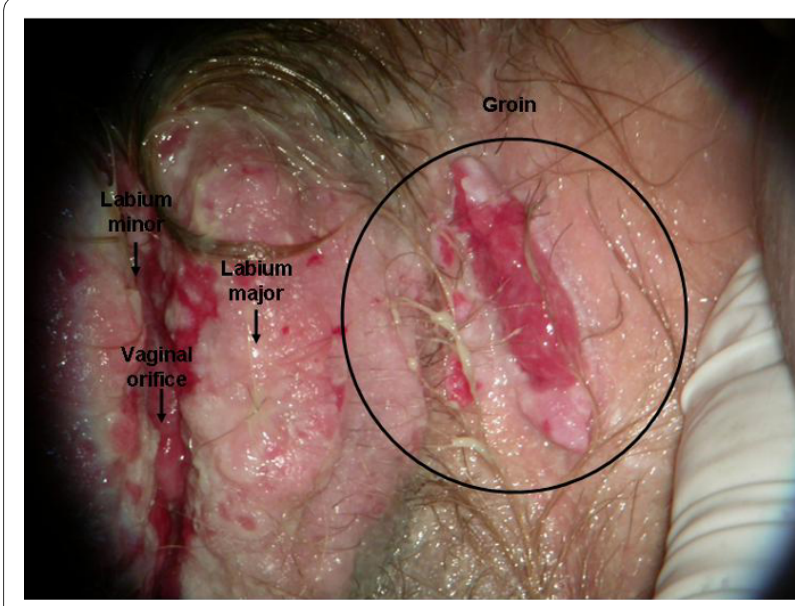

Figure 4 Macroscopic findings after chemotherapy: persistent lesions.

and because the patient had been treated for several years with corticosteroids without similar signs prior to the diagnosis of PV; finally because she showed immunological improvement after increasing the corticosteroid dose. So we diagnosed our patient as affected by PV. As in three of the previously reported cases of PV associated with

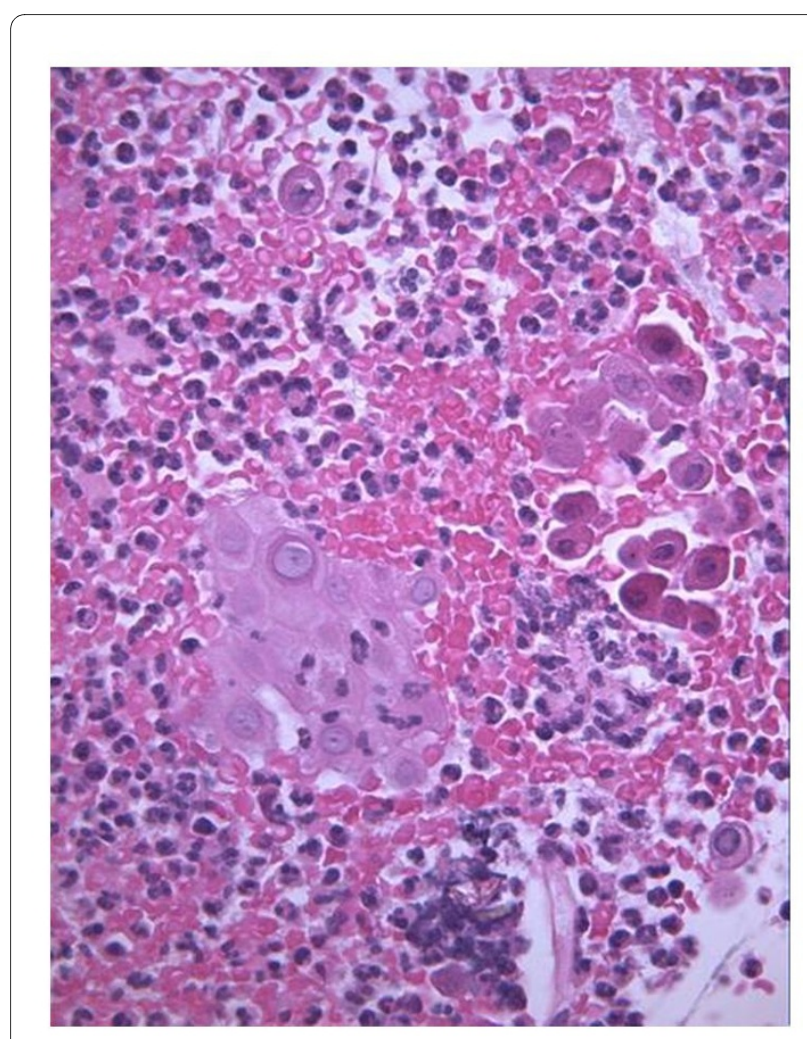

Figure 5 Microscopy findings after chemotherapy: atypical and acantolytic cells dispersed into a neutrophils and red blood cells background.
SLE $[7,11,12]$, SLE presented before PV in our patient. However, in contrast to the other cases [7], PV persisted in our patient after the worsening of the SLE.

The most unusual feature of our patient was the rapid development of VIN 3 and early invasive squamous cell carcinoma (SCC) arising from PV of the vulva. Two different aetiologies of vulvar cancer are known. One type is mainly seen in younger patients (mean age 55 years), is related to HPV infection and smoking, and is commonly associated with basaloid or warty VIN. In contrast, the more common type is seen mainly in elderly patients (mean age 77 years), is unrelated to smoking or HPV infection, and is seldom associated with concurrent VIN, but there is a high incidence of dystrophic lesions (lichen sclerosus, epithelial hyperplasia, lichen planus) [15-21]. Age is the most important predisposing factor in progression from pre-existing VIN to SCC. The best treatment of VIN is conservative surgical excision and follow-up. In case of vertical invasion of the stroma less than $1 \mathrm{~mm}$, a wide and deep excision of the primary tumor is required [22]. Female genital tract involvement in PV has been limited to a small number of case reports, and even rarer cases of female genital tract PV are associated with squamous cell carcinoma [23].

To our knowledge, no case of SCC arising from PV of the vulva has been reported in the literature.

Despite her young age, our patient presented a rapid progression of VIN to microinvasive disease.

In contrast to other cases reported in the literature, our patient did not present HPV infection. The pathogenic mechanism of VIN and its rapid progression to early SCC may be related to the autoimmune disease, to the use of systemic corticosteroids and immunosuppressive agents for therapy and the consequent deregulation of the immune system.

Autoimmune diseases are triggers of chronic inflammation that is a well known risk factor of developing various type of cancer. Since 1863 Virchow noted a connection between inflammation and cancer. He suggested that the "lymphoreticular infiltrate" reflected the origin of cancer at sites of chronic inflammation. The hallmark of cancer related inflammation include the presence of inflammatory cells and inflammatory mediators in tumor tissues, tissue remodelling and angiogenesis similar to that seen in chronic inflammatory responses and tissue repair [24]. There is strong clinical evidence for an association of chronic inflammation with SCC [25]. SCC can arise from a malignant transformation occurred within a chronic inflammatory focus of ulcerative and non healing wounds $[26,27]$. This association has been described for LES, epidermolysis bullosa, lichen planus, leg ulcerations [28-34]. Even areas of healed wounds are more susceptible to development SCC. Moreover, inflammation is not only associated with de novo development 
of SCC but also play a role in his progression [25]. Probably in our patients both LES and PV played a pivotal role in the SCC development.

\section{Conclusion}

Our case underlines PV as another chronic inflammatory disease of the lower genital tract predisposing to VINSCC. It suggests the need for careful follow-up of patients with chronic inflammatory disease, especially when concomitant autoimmune disorders are present. Because of the possibility that neoplasms will develop, a biopsy should be always performed in order to prompt diagnosis and the best treatment.

\section{Abbreviations}

PV: Pemphigus vulgaris; SLE: Systemic lupus erythematosus; SCC: Squamous cell carcinoma; VIN: Vulvar intraepithelial neoplasia; PET: Positron Emmision Tomography; MRI: Magnetic Resonance Imaging; IVIg: Human Immunoglobulins.

\section{Competing interests}

The authors declare that they have no competing interests.

\section{Authors' contributions}

GB revised the manuscript and performed follow-up. VDM conceived of the case report, reviewed the literature and wrote the manuscript. RP diagnosed the disease, performed the follow-up, conceived of the case report and revised the manuscript. PG reviewed the literature, obtained the pictures and collected data. CM performed the histological analysis and wrote the manuscript. MM performed the follow-up and revised the manuscript. LC: performed follow-up. CN revised the manuscript.

All authors read and approved the final manuscript.

\section{Acknowledgements}

Written consent for publication was obtained from the patient

\section{Author Details}

'Department of Gynecology and Obstetrics, and Pathophysiology of Human Reproduction, University of Naples "Federico II", Italy, 2Department of Biomorphological and Functional Sciences, Pathology Section, University of Naples "Federico II", Italy and ${ }^{3}$ Oral Medicine Unit, Department of Odontostomatologica and Maxillo-facial Science, University of Naples "Federico II", Italy

Received: 2 December 2009 Accepted: 23 June 2010

Published: 23 June 2010

\section{References}

1. Wojnarowska F, Venning VA, Burge SM: Immunobullous diseases. In Rook's Textbook of Dermatology 7th edition. Edited by: Burns T, Breathnach SM, Cox NH, Griffiths CEM. Oxford: Blackwell Publishing; 2004:10-41.

2. Chams-Davatchi C, Valikhani M, Daneshpazhooh M, Esmaili N, Balighi K, Hallaji Z, Barzegari M, Akhiani M, Ghodsi Z, Mortazavi H, Naraghi Z: Pemphigus: analysis of 1209 cases. Int J Dermatol 2005, 44:470-476.

3. Stanley JR: Pemphigus. In Fitzpatrick's Dermatology in General Medicine 6th edition. Edited by: Freedberg IM, Eisen AZ, Wolff K, Austen KF, Goldsmith LA, Katz SI. New York: McGraw-Hill; 2003:558.

4. Chan E, Thakur A, Farid L, Lessin S, Uberti-Benz M, James W: Pemphigus vulgaris of the cervix and upper vaginal vault: a cause of atypical Papanicolaou smears. Arch Dermatol 1998, 134:1485-1486.

5. Malik M, Ahmed A: Involvement of the female genital tract in Pemphigus vulgaris. Obstet Gynecol 2005, 106:1005-1012.

6. Batta K, Munday PE, Tatnall FM: Pemphigus vulgaris localized to the vagina presenting as chronic vaginal discharge. Br J Dermatol 1999, 140:945-947.
7. Hidalgo-Tenorio C, Sabio-Sánchez JM, Tercedor-Sánchez J, León-Ruíz L, Pérez-Alvarez F, Jiménez-Alonso J: Pemphigus vulgaris and systemic lupus erythematosus in a 46-y-old man. Lupus 2001, 10:824-826.

8. Robinson JC, Lozada-Nur F, Frieden I: Oral pemphigus vulgaris: a review of the literature and a report on the management of 12 cases. Oral Surg Oral Med Oral Pathol Oral Radiol Endod 1997, 84:349-355.

9. Nanda A, Kapoor MM, Dvorak R, Al-Sabah H, Alsaleh QA: Coexistence of pemphigus vulgaris with systemic lupus erythematosus. Int J Dermatol 2004, 43:393-4.

10. Kuchabal DS, Kuchabal SD, Pandit AM, Nashi HK: Pemphigus vulgaris associated with systemic lupus erythematosus. Int J Dermatol 1998 37:636-8.

11. Fong PH, Chan HL: Systemic lupus erythematosus with pemphigus vulgaris. Arch Dermatol 1985, 121:26-7.

12. Somorin AO, Agbakwu SN, Nwaefuna A: Systemic lupus erythematosus and pemphigus vulgaris preceded by depressive psychosis. Cent Afr J Med 1981, 27:12-4.

13. Mascaró JM Jr, Ferrando J, Solé MT, Alsina M, Nousari HC, Anhalt GJ, Font J, Mascaró JM: Paraneoplastic pemphigus: a case of long-term survival associated with systemic lupus erythematosus and polymyositis. Dermatology 1999, 199:63-66.

14. Ngo AW, Straka C, Fretzin D: Pemphigus erythematosus: a unique association with systemic lupus erythematosus. Cutis 1986, 38:160-163.

15. Carlson JA, Ambros R, Malfetano J, Ross J, Grabowski R, Lamb P, Figge H, Mihm MC Jr: Vulvar lichen sclerosus and squamous cell carcinoma: a cohort, case control and investigational study with historical perspective; implications for chronic inflammation and sclerosus in the development of neoplasia. Human Pathol 1998, 29:932-938.

16. Hørding U, Junge J, Daugaard S, Lundvall F, Poulsen H, Bock JE: Vulva squamous cell carcinoma and papillomaviruses: indications for 2 different aetiologies. Gynecol Oncol 1994, 52:241-246.

17. Carli P, Cattaneo A, De Magnis A, Biggeri A, Taddei G, Giannotti B: Squamous cell carcinoma arising in vulval lichen sclerosus: a longitudinal cohort study. Eur J Cancer Prev 1995, 4:491-495.

18. Byren I, Venning V, Edwards A: Carcinoma of the vulva and asymptomatic lichen sclerosus. Genitourin Med 1993, 69:323-324

19. Gómez Rueda N, García A, Vighi S, Belardi MG, Cardinal L, di Paola G: Epithelial alterations adjacent to invasive squamous cell carcinoma of the vulva. J Reprod Med 1994, 39:526-530.

20. Lewis FM, Harrington $\mathrm{Cl}$ : Squamous cell carcinoma arising in vulval lichen planus. Br J Dermatol 1994, 131:703-705.

21. Campagne G, Roca M, Martínez A: Successful treatment of a high-grade intraepithelial neoplasia with imiquimod, with vulvar pemphigus as a side effect. Eur J Obstet Gynecol Reprod Biol 2003, 109:224-227.

22. Berek JS, Hacker NF: Vulvar Cancer. In Practical Gynecologic Oncology 4th edition. Lippincott Williams \& Wilnkins. Philadephia; 2005:543-583.

23. Hoareau F, Croue A, Marchetta J, Kettani S, Verret JL: Pemphigus vulgaris and intraepithelial neoplasia localized to the vagina. Ann Dermatol Venereol 2007, 134:564-566.

24. Mantovani A, Allavena P, Sica A, Balkwill F: Cancer-related inflammation. Nature 2008, 454:436-444

25. Mueller MM: Inflammation in epithelial skin tumours: Old stories and new ideas. EJC 2006, 42:735-744.

26. Marjolin JN: Ulcere. Dictionnaire de Medecine. Paris 1828:31-50

27. Clements B, Lewis H, McKinstrey S, Gray J, Byrnes D: A late, fatal complication of a high energy thermal injury to the scalp. Ann Plast Surg 1995, 35:650-3.

28. Kaplan RP: Cancer complicating chronic ulcerative and scarifying mucocutaneous disorders. Adv Dermatol 1987, 2:19-46.

29. Gur E, Neligan PC, Shafir R, Reznick R, Cohen M, Shpitzer T: Squamous cell carcinoma in perineal inflammatory disease. Ann Plast Surg 1997, 38:653-7.

30. Sarani B, Orkin BA: Squamous cell carcinoma arising in an unhealed wound in Crohn's disease. South Med J 1997, 90:940-2.

31. Mayron R, Grimwood RE, Siegle RJ, Camisa C: Verrucous carcinoma arising in ulcerative lichen planus of the soles. J Dermatol Surg Oncol 1988, 14:547-51.

32. Yamada T, Suzuki M, Hiraga M, Toda S, Fujimoto M, Ohtsuki M, Kiyosawa T, Harada S, Nakagawa $\mathrm{H}$ : Squamous cell carcinoma arising on scars of epidermolysis bullosa acquisita. Br J Dermatol 2005, 152:588-90. 
33. Mallipeddi R, Keane FM, McGrath JA, Mayou BJ, Eady RA: Increased risk of squamous cell carcinoma in junctional epidermolysis bullosa. J Eur Acad Dermatol Venereol 2004, 18:521-6.

34. Goldberg Gl, Eisen AZ, Bauer EA: Tissue stress and tumor promotion. Possible relevance to epidermolysis bullosa. Arch Dermatol 1988, 124:737-41.

\section{Pre-publication history}

The pre-publication history for this paper can be accessed here: http://www.biomedcentral.com/1471-2407/10/324/prepub

\section{doi: 10.1186/1471-2407-10-324}

Cite this article as: Bifulco et al., Early invasive vulvar squamous cell carcinoma arising in a woman with vulvar pemphigus vulgaris and systemic lupus erythematosus BMC Cancer 2010, 10:324

Submit your next manuscript to BioMed Central and take full advantage of:

- Convenient online submission

- Thorough peer review

- No space constraints or color figure charges

- Immediate publication on acceptance

- Inclusion in PubMed, CAS, Scopus and Google Scholar

- Research which is freely available for redistribution

Submit your manuscript at www.biomedcentral.com/submit
C) Biomed Central 